\title{
Davi tirando sarro de Golias: o risoativismo dos Yes Men
}

\section{David mocking Goliath: Yes Men's laughtivism}

Fabio Salvatti ${ }^{1}$ 


\section{Resumo}

A partir do uso ativista do humor, o coletivo Yes Men realiza ações de correção de identidade, isto é, assumem a identidade de representantes de corporações, órgãos governamentais e instituições financeiras para expor as engrenagens da entidade para escrutínio público em falsas palestras, entrevistas e declarações à imprensa. Com isso buscam uma alteração na disposição do espectro de alianças relacionadas ao assunto sobre $o$ qual estão tratando. No presente artigo, busca-se demonstrar que, para além das ações orientadas para uma disputa no campo simbólico, os Yes Men propõem um projeto pedagógico, materializado no Yes Lab, um laboratório de ativismo criativo por eles mantido.

Palavras-chave: Performance; Ativismo Político; Risoativismo

\section{Abstract}

Through the activist use of humor the collective The Yes Men performs identity corrective actions, that is, they assume the identity of representatives of corporations, government agencies and financial institutions in order to expose their gears to public scrutiny on false lectures, interviews and press conferences. With that they seek to shift the spectrum of allies related to the matter on which they are working. In this paper we seek to demonstrate that in addition to actions aimed at a dispute in the symbolic field, the Yes Men propose a pedagogical project, materialized on the Yes Lab, a creative activism laboratory they maintain.

Keywords: Performance; Political Activism; Laughtivism

ISSN: 1414.5731

E-ISSN: 2358.6958

${ }^{1}$ Professor Doutor Adjunto III do Departamento de Artes da Universidade Federal de Santa Catarina (UFSC), diretor teatral. fabiosalvatti@gmail.com 
É mais fácil enganar as pessoas do que convencê-las de que foram enganadas.

Mark Twain (será?)

O governo do ditador Slobodan Milosevic na lugoslávia não parecia o cenário mais hospitaleiro para o surgimento de um movimento ativista que tinha o riso como plataforma. Milosevic teve papel determinante nas guerras que assolaram os Balcãs nos anos 90, já que ele foi presidente da Sérvia entre 1989 a 1997, e presidente da lugoslávia (que então englobava as repúblicas da Sérvia e de Montenegro) de 1997 a 2000. Pesou sobre ele acusações de crimes de guerra e crimes contra a humanidade pelo Tribunal Criminal Internacional da Antiga lugoslávia, formado pela ONU². Dentre suas práticas políticas reprováveis estavam a tomada do controle administrativo e acadêmico de todas as universidades do país e o banimento de todos os jornais que se aventurassem a criticar seu governo. A polícia que servia o "açougueiro dos Balcãs", como Milosevic era conhecido, não hesitava em perseguir, prender, torturar e matar seus opositores.

No entanto, foram nestas condições, no final de 1998, que surgiu o Otpor!, organização que primeiro se apresentou como um grupo de protesto, depois, após a queda de Milosevic, passou a ser um observatório político e se tornou, finalmente, um partido político. O Otpor!, que significa "resistência", foi criado logo após a tomada do controle das universidades pelo governo iugoslavo, com princípios de nãoviolência e unidade de ação. Eles acreditavam que o ativismo não precisava ser chato e, como uma primeira ação para aplicar isso na prática, criaram o Milosevic-no-barril. Eles pegaram um daqueles barris de latão, usados em construções, e colaram uma imagem do ditador em sua lateral. Sobre o barril, uma pequena fenda para moedas e um cartaz que dizia "arrebente a cara dele por um dinar"3. Levaram o barril com a cara de Milosevic e um taco de beisebol até uma rua movimentada de Belgrado, os posicionaram estrategicamente na calçada e se dirigiram para um café em frente. Os primeiros transeuntes olharam desconfiados, sem se aproximar muito do barril. Logo alguém veio e pegou o bastão, ainda sem bater no barril. Por fim, apareceu um corajoso que bateu e saiu correndo. Alguém deu risada, já procurando nos bolsos por uma moeda para também participar. O primeiro pagante deu uma tacada com gosto na cara de Milosevic. O estrondo chamou a atenção, e logo haviam mais voluntários. Em seguida, uma fila deles. Pais, rindo, encorajavam seus filhos a bater na cara do ditador. $O$ som dos golpes continuava ressoando quando, enfim, a polícia chegou. Eles então tinham duas escolhas: ou prendiam as pessoas na fila, composta por senhoras, adolescentes com sacolas de compras, famílias, velhinhos simpáticos; ou apreendiam o barril. Não havia opção em que os policiais não perdessem . Como a prisão daqueles cidadãos pacíficos, não-ativistas, seria encarada como um ultraje, até porque não havia leis que impedissem a população de dar tacadas em barris, os policiais dispersaram a fila e carregaram o barril, segurando um de cada lado. Um fotógrafo flagrou a cena e conseguiu disseminar a imagem. "Aquela imagem valia, de fato, mais do que mil palavras: dizia a qualquer um que a temida polícia de Milosevic

\footnotetext{
${ }^{2}$ Dentre as acusações estavam genocídio, assassinatos, perseguição política, racial e religiosa, tortura, tratamento desumano e a deportação forçada de 800 mil albaneses de Kosovo. Milosevic morreu em 2006, antes do final do julgamento. Em 2007 a Corte Internacional inocentou Milosevic de responsabilidade direta nos crimes, mas concluiu que ele tinha plena consciência da ocorrência dos crimes e não fez nada para impedi-los.

${ }^{3}$ Um dinar é o equivalente a 3 centavos de Real.
} 
consistia apenas em um bando de panacas ineptos" (Popovic e Miller, 2015, p. 103).

Quem conta a história é Srdja Popovic, um dos fundadores do Otpor! e hoje dirigente do CANVAS (sigla em inglês para Centro Aplicado de Estratégias e Ações Não-Violentas - a palavra também significa tela de pintura), organização educacional não governamental e sem fins lucrativos que atua internacionalmente no treinamento de ativistas. Popovic justifica a opção do Otpor! Através de táticas cômicas de uma maneira muito pragmática: "Se você é um policial, você passa o tempo pensando em como vai lidar com pessoas violentas, mas nada no seu treinamento te prepara para lidar com pessoas engraçadas. Esse é o gênio do risoativismo" (Popovic e Miller, 2015, p. 99). O Otpor! foi o responsável por cunhar o termo, que une as palavras laugh (risada) e activism (ativismo) - laughtivism - logo, risoativismo ${ }^{5}$.

Otpor! compreendeu que qualquer ditadura é como uma marca, dependente de exposição midiática e de uma narrativa de estabilidade. Para resistir a esta marca era necessária uma disputa simbólica com três premissas. Primeiro, que evitasse operar na violência, que, junto com o medo é o domínio de excelência dos regimes ditatoriais; segundo, que fosse capaz de reunir pessoas ao redor de uma visão de futuro comum; e, terceiro, que conseguisse sacudir os pilares econômicos que sustentam o regime.

Para o Otpor!, o risoativismo era o caminho mais adequado para esta disputa simbólica. Na avaliação do grupo, o riso corrói o medo e constrói a confiança; confere uma atmosfera cool, que ajuda a atrair novos membros para o movimento; e força dilemas de decisão, que leva a más reações do regime e consequente perda de credibilidade política e suporte econômico.

O humor político é tão velho quanto a política. Sátiras e piadas vem sendo usadas para falar a verdade ao poder por séculos. Mas os risoativistas da era moderna elevaram o humor a um novo nível. O riso e a diversão não são mais marginais na estratégia de um movimento. Em muitos casos, eles são a estratégia. Os ativistas não-violentos estão liderando uma mudança global nas táticas de protesto, saindo da raiva, do ressentimento, da ira para uma forma mais poderosa de ativismo baseada na diversão. [Popovic e Miller, 2015, p. 123].

Se avaliada do ponto de vista da eficácia, é possível dizer que a experiência do Otpor! foi bem sucedida. O engajamento da população iugoslava nos protestos fez com que Milosevic fosse forçado a renunciar em outubro de 2000, logo após uma controversa eleição presidencial que ele considerava ganha. Do mesmo modo, é possível valorizar a eficácia da experiência pedagógica do CANVAS. Exemplo disso é que o centro de treinamento recebeu para um workshop, em julho de 2009, um grupo de ativistas egípcios que, um ano e meio mais tarde, esteve na organização do levante popular que colocou o Egito no mapa da Primavera Árabe e que resultou na derrubada do presidente Hosni Mumbarak, que estava no poder fazia 30 anos.

Do outro lado do Atlântico, há um grupo de ativistas que Popovic chama de "a versão estadounidense do Monty Python" [Popovic e Miller, 2015, p. 116] e ressalta a irreverência desafiadora de suas ações. Trata-se dos Yes Men, que mantém com

\footnotetext{
${ }^{4}$ Tratava-se de um dilema de decisão, conceito sobre o qual discorro mais adiante.

${ }^{5}$ Tentei algumas traduções, risoativismo acabou sendo a menos pior. Srdja Popovic reivindica ativamente a autoria do conceito, motivo pelo qual eu aqui atribuo sua origem ao Otpor!. Popovic e Miller, 2015, 2015, p. 110.
} 
membros do Otpor! uma admiração mútua. Ainda que bastante diferentes em suas práticas, os grupos têm em comum a reivindicação do risoativismo como princípio orientador de suas ações. Os Yes Men, de modo muito informal, consideram que o risoativismo "faz as pessoas rirem de assuntos importantes. [...] Se há um problema crítico que não está recebendo atenção suficiente da imprensa, nós pensamos em um modo de fazer algo muito engraçado que faça a imprensa atentar a ele"6. De modo similar, Srdja Popovic e Marcella Alvarez, também diretora do CANVAS, assim expressam o conceito:

Em vez da caricatura do panorama político em nome do entretenimento ou da arte, como tem sido feito há literalmente milênios, o objetivo com as técnicas risoativistas é conscientizar a respeito de um assunto político ou social usando o humor para passar a mensagem. Algumas características das técnicas risoativistas: elas são divertidas; elas são políticas; elas têm natureza demonstrativa e trazem consciência através do uso de campanhas criativas e reais. [Popovic e Alvarez, 2014].

É possível perceber em ambas formulações uma intenção de publicidade, isto é, de tornar público algo até então oculto. Quer dizer, o risoativismo busca a divulgação de uma determinada denúncia, de determinado chamado à ação ou de determinado posicionamento político através do recurso do humor. Ao fazer isso, certamente um dos desejos é de que a própria ação risoativista executada sirva para divertir os agentes. Além disso, ações risoativistas também buscam a simpatia daqueles que não necessariamente estão envolvidos ou posicionados sobre o assunto reclamado por elas. Nesta perspectiva, as ações buscam tanto informar quanto convencer os não-ativistas. Ou seja, o humor, a ironia, o sarcasmo, permitem que uma mesma ação contenha muitas camadas significantes. $O$ riso pode ser uma estratégia de acessibilidade para temas ou posições consideradas usualmente como radicais.

Em termos de influências, é possível afirmar que tanto o Otpor! quanto os Yes Men tem inspirações no ativismo dos anos 60, em especial nos yippies e nos situacionistas. No entanto, dada a crítica de Debord aos meios de comunicação de massa e seu aspecto espetacular, seria possível suspeitar de uma contradição entre o endereçamento tão direto das ações do Otpor! e dos Yes Men para cobertura midiática e suas filiações situacionistas. Esse conflito é conceitualmente problematizado pelo que o professor Stephen Ducombe chama de espetáculo ético. O pressuposto do conceito é de que o ativismo contemporâneo que pretende ser politicamente efetivo precisa se engajar em algum grau com o espetáculo. Para Ducombe, as premissas do espetáculo ético são:

1) que a política é um assunto de desejo e fantasia tanto quanto de razão e racionalidade; 2) que vivemos em uma época de intensa midiatização (o que o situacionista Guy Debord chamou de Sociedade do espetáculo; 3) que para serem politicamente efetivos, os ativistas precisam entrar no domínio do espetáculo; 4) que intervenções espetaculares têm o potencial de serem éticas e emancipatórias ao mesmo tempo. (Ducombe, 2012, p. 230)

${ }^{6}$ Yes Men, não publicado, 2015. 
Neste sentido, em vez dos movimentos progressistas recusarem qualquer tática que envolva propaganda ou marketing, deveriam se apropriar destas ferramentas para resistir com o mesmo grau de sofisticação simbólica que o capital adota. De acordo com Ducombe, "a verdade não se revela simplesmente por ser a verdade: ela precisa ser contada, e bem contada" (Ducombe, 2012, p. 231).

Os Yes Men ${ }^{7}$ utilizavam estas ferramentas espetaculares desde antes da sua formação como coletivo. Em 1993, Mike Bonanno comprou dezenas de bonecas Barbies e bonecos GI Joe e cirurgicamente trocou suas caixas de vozes. Depois, recolocou os produtos nas prateleiras das lojas. No Natal, algumas crianças foram surpreendidas quando suas bonecas disseram "Homens mortos não mentem!" e seus soldados disseram "Eu adoro fazer compras com você!". A ação foi assumida, mais tarde, pela Organização para a Libertação das Barbies (BLO em inglês) e repercutiu nacionalmente nos EUA. Em 1996, Andy Bichlbaum, então programador de uma empresa de videogames, incluiu, como personagens figurantes que completavam o cenário do jogo SimCopter, homens de sunga que saíam às ruas para se beijarem. Assim como a ação do BLO, o caso atraiu a curiosidade da mídia.

$\mathrm{Na}$ época, Andy já havia fundado um website, chamado de ${ }^{\mathrm{TM} M \mathrm{ark}^{8}}$, que anunciava ser uma bolsa de valores para sabotagens, ou seja, era um lugar para o encontro de ativistas e pranksters, que supostamente "patrocinavam" ações como as descritas. Andy já tinha atribuído uma suposta doação de 5 mil dólares para seu golpe no SimCopter, e mais tarde, através de amigos em comum, chegou até Mike, a quem perguntou se, por algum acaso, a ${ }^{\circledR T M}$ ark não teria contribuído com 10 mil dólares para o prank da Organização para a Libertação das Barbies. Deste modo surgiu a frutífera colaboração entre os dois.

Em 1999 um ativista chamado Zack Exley procurou a ${ }^{\mathrm{T} M a r k}$ para ajudá-lo a colocar no ar um site que ele já havia registrado: GWBush.com. O verdadeiro site do então candidato a presidência dos EUA era GeorgeWBush.com, e contava as proezas de seu período como governador do Texas. O site pirata fez uma paródia do site original, aproveitando seu layout, mas substituindo informações essenciais, como o vínculo da família Bush com o governo nazista, a poluição gerada no Texas durante seu mandato, e seu vício em cocaína. A reação de George W. Bush acabou por complicar sua imagem pública e lançar os risoativistas no foco da mídia internacional. Sobre o assunto, ele proferiu uma infeliz declaração que se tornou célebre: “Deveria haver limites para a liberdade".

Depois do sucesso do golpe, a ${ }^{\mathrm{T} M}$ ark foi procurada por Jonathan Prince, que havia registrado o endereço GATT.org e pretendia fazer com ele algo equivalente ao que havia sido feito com Bush. Aí começou de fato a história dos Yes Men.

GATT é a sigla em inglês para Acordo Geral de Tarifas e Comércio, um acordo negociado após a segunda guerra mundial para disciplinar o comércio entre as nações, o que permitiu o crescimento vertiginoso das grandes corporações na segunda metade do século XX. Depois da derrocada do socialismo soviético, o capitalismo

${ }^{7}$ A história dos Yes Men, relatada ao longo das próximas páginas, teve como fonte tanto os filmes feitos pelo grupo, The Yes Men (direção de Dan Ollman, Sarah Price e Chris Smith, 2003); The Yes Men fix the world (direção de Andy Bichlbaum e Mike Bonanno, 2009); e The Yes Men are revolting (direção de Andy Bichlbaum, Mike Bonanno e Laura Nix, 2014); quanto o livro The Yes Men: the true story of the end of the World Trade Organization (escrito pelos Yes Men em 2004). ${ }^{8} \mathrm{Há}$ um trocadilho aqui. A fonética dos símbolos equivale a "Art Mark", diminutivo para mercado de arte. Além disso, é claro, os símbolos se referem a Marca Registrada. 
corporativo entendeu que estava na hora de dar o passo seguinte, e a partir do GATT, propôs a formação da OMC - Organização Mundial do Comércio (WTO, em inglês), agência sediada em Genebra, Suiça, e responsável por garantir o livre-mercado que marcou a economia mundial a partir dos anos 1990. O livre-mercado era propício para indivíduos e corporações que pretendiam fazer transações comerciais sem as barreiras nacionais. No entanto, era bastante perverso para a garantia dos direitos trabalhistas (tanto nos países centrais quanto nos periféricos do sistema capitalista), para a preservação do ambiente e para a manutenção da seguridade social.

Como a sigla GATT ainda era mais conhecida do que a recém criada OMC, os executivos preferiram manter o site oficial da instituição com a sigla antiga. Por isso, o registro de um endereço muito similar como GATT.org era uma excelente oportunidade para paródia. A reação da OMC ao site foi, assim como a de Bush no episódio relatado anteriormente, responsável pelo sucesso da empreitada. A Organização lançou um comunicado de imprensa deplorando as atividades do site pirata, alegando que criava confusão e debilitava a transparência da instituição. Isso fez com que jornalistas do mundo inteiro atentassem ao site pirata e reportassem os textos críticos ali presentes. Outra consequência importante foi elevar a colocação do GATT.org nos rankings dos mecanismos de busca.

Esta última consequência demonstrou ser a maior conquista do grupo. Aparentemente, algumas instituições, representantes governamentais, advogados e acadêmicos, quando procuravam pela OMC, faziam apenas uma breve busca na internet e não tinham tempo ou disposição suficientes para investir na leitura dos textos paródicos contidos no falso site. Então enviavam perguntas para o e-mail disponível no link de contato, pensando estar se comunicando com as autoridades de Genebra. Os Yes Men ofereciam prontas respostas a estas demandas, mantendo a ilusão de que o remetente enviara sua correspondência para o endereço correto. Foi quando, através deste e-mail, os Yes Men começaram a ser convidados a enviar representantes da OMC para eventos, congressos e conferências. Pelos três anos que se seguiram, a "OMC" aceitou estes convites, enviando representantes dispostos a revelar sem hesitação a verdadeira face da instituição.

A esta tática de personificar falsos porta-vozes, que começou com a OMC, mas que logo foi replicada com corporações, órgãos governamentais e instituições financeiras ${ }^{9}$, os Yes Men deram o nome de correção de identidade. Consistia na exposição das engrenagens da entidade para escrutínio público em falsas palestras, entrevistas e declarações à imprensa.

Corrigir uma identidade significa trazer a verdade à tona. A OMC está fazendo coisas terríveis a muitas pessoas, mas ela mostra o oposto. Nós estamos interessados em corrigir sua identidade. Do mesmo modo que um ladrão rouba a identidade de alguém para participar de atividades criminosas, escolhemos as pessoas que vemos como criminosas e roubamos suas identidades para torná-los honestos, ou para tentar apresentar um lado mais honesto da história ${ }^{10}$.

Simulando seus representantes, os Yes Men diziam coisas que a entidade até

\footnotetext{
${ }^{9}$ A tática de simular/parodiar o website destes alvos e disponibilizar um e-mail para contato se mostrou muito profícua. Várias destas paródias estão em http://yeslab.org/museum
} ${ }^{8}$ Declaração de Mike Bonanno no primeiro filme sobre os Yes Men. Ollman, Price e Smith, 2003. 
poderia dizer, mas que jamais o faria, porque se o fizessem seriam reveladas posições políticas e econômicas que ela preferiria que permanecessem ocultas. $O$ mecanismo da correção de identidade atua na percepção pública de determinada instituição, quer dizer, é uma tentativa de adequar a imagem destas instituições à conduta ética de suas práticas. De certo modo, trata-se de um hacking institucional. Além disso, os Yes Men querem garantir que vão se divertir neste processo:

O que é dito ou é algo que o alvo diria se o departamento de relações públicas estivesse maluco (proposta modesta) ou algo que eles diriam se, por algum milagre, eles decidissem fazer o correto (proposta honesta). Em vez de falar a verdade ao poder, $[\ldots]$ assumir a máscara do poder para falar uma pequena mentira que conta uma verdade maior. A proposta modesta, que os Yes Men e outros usaram em muitas ocasiões para personificar corporações e parodiá-las, pode ser um assunto pontual. Geralmente envolve uma expressão absurda e extrema, mas lógica, das próprias práticas da entidade.

Apesar das recompensas emocionalmente gratificantes de palhaçadas como estas, são as propostas honestas (assumir a identidade de um grande vilão para anunciar que ele fará algo maravilhoso) que provaram ser mais efetivas para constranger um alvo. (Bichlbaum, 2012, p. 60)

Para verificar como operam estas modalidades categorizadas por Bichlbaum (propostas modesta e honesta), é instrumental analisar o exemplo de correção de identidade da Dow Chemicals, a ação dos Yes Men de maior repercussão midiática até o momento. A Dow é uma mega-corporação de produtos químicos que atua em inúmeros setores industriais. Em 2001, adquiriu a Union Carbide, empresa responsável por um vazamento de gás em uma usina em Bhopal, na Índia, em 1984. Mais de 15 mil pessoas morreram em decorrência da exposição ao material tóxico e aproximadamente 120 mil tiveram danos médicos crônicos irreparáveis, o que alçou Bhopal à marca de maior desastre industrial da historia. Em nenhum momento a Union Carbide assumiu total responsabilidade pelo ocorrido. A Dow Chemicals, no entanto, veio a publico em 03 de dezembro de 2004 para aceitar totalmente o ônus que pesava sobre a subsidiaria adquirida. Jude Finisterra, porta-voz da empresa (personificado por Andy Bichlbaum), foi ao vivo aos estúdios da BBC afirmar que "estava muito feliz em anunciar que a Dow estava aceitando plena responsabilidade sobre a catástrofe em Bhopal" e que a empresa tinha um plano de 12 bilhões de dólares para compensar as vítimas e despoluir a área que ainda apresentava resíduos tóxicos. Como consequência, a Dow teve uma queda de 4,2\% no valor de suas ações na bolsa, o que representou um prejuízo de 2 bilhões de dólares ${ }^{11}$.

A falha da BBC foi ter enviado, no final de novembro de 2004, um pedido de entrevista com um representante da Dow para o endereço de contato que encontrou no site-isca dowethics.com. Os jornalistas já estavam acostumados com as recusas da empresa em falar sobre Bhopal ou com as respostas-padrão do tipo "o desastre com gás nas instalações da Union Carbide Índia Limited em Bhopal foi uma tragédia que não deve jamais ser esquecida"12. Por isso comemoraram a prontidão e as declarações de Finisterra. 


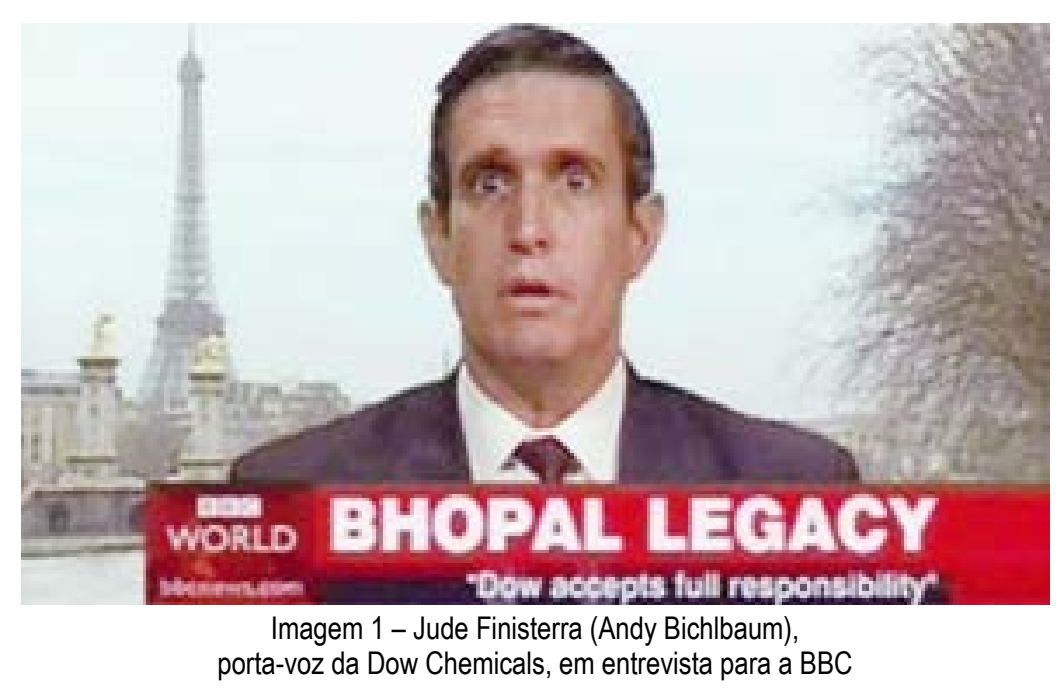

Após a entrevista repercutir internacionalmente, a Dow Chemicals enviou um comunicado à imprensa para desmentir as afirmações do porta-voz impostor. "A única responsabilidade de Dow é com seus acionistas, e a empresa não pode fazer nada que vá contra seus princípios, a não ser 'forçada pela lei" (Bonanno, 2012, p. 319).

A dura resposta da empresa, deixou claro sua indiferença aos direitos humanos, ganhou repercussão midiática, e se tornou a notícia mais lida do Google Notícias daquele dia. Acontece que o comunicado à imprensa também havia sido escrito pelos Yes Men, e replicado prontamente pelos veículos de imprensa sem a devida apuração das informações.

Depois da revelação de ambas as imposturas, a BBC solicitou uma entrevista com Bichlbaum, na qual ele sustentou que o verdadeiro trote era da Dow, quando afirmam que não podem assumir a responsabilidade por Bhopal, o que fez a população sofrer por vinte anos.

O portfólio de ações dos Yes Men é bastante extenso ${ }^{13}$, e apesar de alvos diferentes e de algumas variações táticas, as ações apresentam características similares que podem ser identificadas. Com o exemplo da Dow, percebemos a aplicação das duas modalidades de correção de identidade formuladas por Bichlbaum. Na entrevista à BBC, estava em jogo a "proposta honesta", um pequeno milagre no qual uma grande corporação assume seus próprios erros e é voluntária para a reparação. $O$ ativista Andrew Boyd chama isto de intervenção prefigurativa, isto é, a criação de ações que proporcionem um breve olhar ou uma breve experiência de um mundo tal qual gostaríamos que ele fosse. (BOYD, 2012, p. 84). Em vez de um exercício de imaginação, o que a intervenção prefigurativa faz é transportar o público para uma realidade na qual operam as condições expressas na ação, de modo que ele possa perguntar "por que não?". "Precisávamos mostrar com o que uma verdadeira mudança se parece. [...] Nós podemos fazer todas essas coisas. Se nós criamos o sistema

\footnotetext{
${ }^{11}$ Uma descrição mais completa desta ação está presente em minha tese de doutorado. Salvatti, 2010, p. 64 e no segundo filme do grupo, Yes Men fix the world. Bichlbaum e Bonanno, 2009.

${ }^{12}$ Declaração oficial da Dow sobre o desastre publicada no site da empresa, mas retirada após a ação dos Yes Men. Ela foi coletada do artigo "Dow Chemical just says 'Yes' to Bhopal" assinado pelos Yes Men e disponível em http://theyesmen.org/dowtext/. Este texto foi selecionado para a coletânea Network Art: practices and positions, editada por Tom Corby e publicada pela editora Routledge em 2006. No entanto, a redação do artigo sofreu várias alterações na versão impressa. Os Yes Men incluíram um adendo ao artigo original, intitulado "Routledge just say "Yes" to Dow: the collaboration of a progressive academic press and a large chemical corporation", no qual denunciam o teor e as motivações das modificações no texto, que aliviam as críticas contundentes contra a Dow (presumivelmente por receio de medidas judiciais contra a editora), e ainda oferecem as duas versões, a original e a modificada, para comparação.
} 
que temos agora, porque não, em vez deste, criar um sistema bom?" (Bichlbaum e Bonanno, 2009). Também são propostas honestas, ou intervenções prefigurativas, a publicação, em 2009, de uma falsa edição do New York Times, "com as notícias que gostaríamos de ver impressas"14; e o "Segundo Dia de Ação de Graça", ação que demonstrou ser possível reunir políticos e lobistas em uma dança de roda, celebrando as energias renováveis e a preservação do planeta.

Foi no conteúdo do comunicado de imprensa desmentindo a fala de Finisterra que se manifestou a segunda modalidade de correção de identidade, a "proposta modesta". Ao se antecipar à reação da Dow Chemicals e pela segunda vez portar sua voz, os Yes Men conseguiram expor e radicalizar os princípios da empresa, ou seja, o compromisso com o lucro independente das consequências ambientais ou humanas.

Outra característica comum a praticamente todas as ações propostas pelos Yes Men que também é demonstrada pela ação contra a Dow é a de ter como meta a colocação do alvo em um dilema de decisão. No exemplo em questão, qualquer atitude que a Dow tomasse a respeito do assunto representaria uma perda para ela. Ou seja, caso a empresa decidisse negar que estava destinando recursos para a reparação de Bhopal, ela estaria endossando o falso comunicado de imprensa, e revelando uma face de descaso com os direitos humanos e com o ambiente que ela preferia que permanecesse oculta; caso ela destinasse de fato os 12 bilhões para Bhopal, ela ganharia em termos de imagem, mas perderia em lucro e daria poder simbólico aos risoativistas, abrindo um precedente talvez incontrolável para demais instituições; caso ela simplesmente ignorasse o episódio, seria tida como omissa e perderia sua credibilidade.

Esta "situação de perde-ou-perde"15 é justamente um dos objetivos finais do risoativismo dos Yes Men. Diferentemente da Teoria dos Jogos, na qual a situação de perde-ou-perde significa que todos os jogadores envolvidos terão reveses com determinada tomada de decisão, no risoativismo dos Yes Men a intenção é de que apenas o jogador adversário, isto é, o alvo, sofra estas consequências. Portanto, a verdadeira ação dos Yes Men é a reação das instituições que eles personificam. Antecipar estas reações para que elas forçosamente se apresentem como dilemas de decisão é o que faz da correção de identidade uma tática tão interessante.

Entre as reações possíveis das entidades personificadas estão as ameaças de processos judiciais. De maneira contra-intuitiva, elas não são motivo para preocupação, mas para celebração ${ }^{16}$. Na experiência dos Yes Men, estas ameaças costumam se concretizar em forma de notificações extrajudiciais, que, ainda que estejam escritas em juridiquês e tenham a assinatura de um advogado, não têm valor legal. Tendem a ser apenas um blefe já que, geralmente, as entidades tem mais a perder quando envolvidas em um processo judicial, mesmo como requerente. Este blefe costuma ser usado pelo grupo, que aproveita trechos das notificações como citações em seus comunicados de imprensa, e a disputa passa a ser publicamente percebida como Davi versus Golias.

\footnotetext{
${ }^{13}$ E está bastante documentado no site http://yeslab.org. Os "maiores sucessos" dos Yes Men estão reunidos nos filmes produzidos pelo grupo, citados na nota 13. ${ }^{14} \mathrm{~A}$ versão digital da falsa edição do jornal está em http://www.nytimes-se.com

${ }^{15}$ Tradução nossa improvisada de lose-lose situation.
} 
Quando relatadas, as ações dos Yes Men parecem depender de uma dose descomunal de coragem e de "trabalho de ator", predominantemente de Bichlbaum, que veste a figura de porta-voz mais frequentemente. Eles não concordam. “Quando você vai a uma conferência fingindo ser outra pessoa, é muito importante ter um cartão de visita. Isto é fundamental. Fora isto, não há muitas coisas necessárias" (VALE, 2006, p. 36). Nem mesmo a preparação para atuar é considerada prioridade pelo grupo. Primeiro porque os relações públicas, porta-vozes e representantes de empresa também costumam ficar nervosos e demonstrar dificuldades em frente a câmeras ou plateias. Segundo, porque naquele momento de fala, seja em uma entrevista ou em uma palestra, o porta-voz é o representante oficial, o especialista no assunto, "a pessoa mais importante da sala", e não há porque colocar em dúvida sua autoridade. Enquanto no teatro o público sabe que o ator não é Hamlet ou Édipo, e só com um esforço e uma competência significativa do artista ele consegue "suspender a descrença" da plateia, na correção de identidade o público já vem com sua descrença suspensa por princípio. Ou talvez a descrença nem chegue a existir. O público sabe que está diante de uma autoridade. Desde que bem ensaiado, o que, de acordo com Bichlbaum, é condição para que o nervosismo não arruíne a performance, o portavoz pode dizer qualquer coisa sem que sua identidade seja questionada.

Para nossa surpresa, em todos os eventos em que falamos não tivemos nenhuma dificuldade em enganar os experts. [...] Pior: não conseguimos fazer com que não acreditassem em nós. [...] Toda vez esperávamos ser presos, expulsos, silenciados, ou pelo menos interrompidos. Mas a ficha não caía. Ao contrário, eles aplaudiam. Se a plateia tão facilmente se deixava tão facilmente levar pelos caminhos sinistros [que apresentávamos], a verdadeira OMC deve ser capaz de convencê-la de qualquer coisa. (The yes Men, 2004, p. 8)

Esta constatação foi desdobrada de modo ainda mais perturbador na entrevista que concederam para a revista Artforum em fevereiro 2005. Quando perguntados se nunca ninguém que esteve presente às palestras em nome da Organização Mundial do Comércio flagrou a piada, os Yes Men responderam:

Certamente algumas pessoas devem ter achado absurdo. Mas o fato é que as convenções sociais que os impedem de falar são assustadoras. Com isso aprendemos que todos nós podemos implicitamente apoiar ideias extremamente violentas e flagrantemente absurdas em um auditório repleto de experts e não haver ninguém que publicamente expresse sua discordância. Tudo isso foi provado várias vezes: na história, quando regimes violentos são apoiados pela maioria da população; e em laboratório, em experimentos como os de Milgram. (Vanderbilt, 2005)

As características da facilidade de suspensão da descrença e obediência à autoridade, bastantes distintas daquelas vividas pela plateia teatral, sugerem a pergunta: qual, então, a plateia dos Yes Men? A quem se destinam suas ações?

Os Yes Men trabalham com um espectro de alianças. Eles consideram cinco divisões entre aqueles que se relacionam com suas ações. Em um extremo estão os aliados ativos, aqueles que concordam com as proposições e se engajam com elas executando ações ou tarefas; em seguida, estão os aliados passivos, aqueles que,

\footnotetext{
${ }^{16}$ Aqui é preciso ressaltar que os EUA são um país no qual a liberdade de expressão está muito bem protegida legalmente. Talvez esta despreocupação não tivesse o mesmo tom se o ambiente fosse mais restritivos em termos judiciais ou mais perigoso em termos sociais.
} 
apesar de estarem de acordo com o ponto de vista do grupo, não se engajam em ações; em seguida há os neutros, que não tomam partido a respeito dos assuntos abordados; em seguida os opositores passivos, que discordam mas não agem; e, por fim, os opositores ativos, que são os que se engajam ativamente de modo contrário ao proposto. Não adiantaria, de acordo com os Yes Men, se dirigir apenas para a primeira fatia de aliados, o que seria o famoso "pregar para os convertidos". Do mesmo modo, pensar somente em combater a última fatia, dos opositores ativos, só demonstra sectarismo e uma falsa oposição de "nós contra eles". A pretensão dos Yes Men seria, portanto, fazer os receptores das ações se deslocarem no espectro de alianças cada vez mais para o lado dos aliados ativos. Isto é, tentar fazer dos aliados passivos, aliados ativos; dos neutros, aliados passivos; dos opositores passivos, neutros; e dos opositores ativos, opositores passivos. Para os risoativistas, o uso tático da comédia poderia proporcionar este deslocamento, dado o poder de sedução do humor.

A Diretora da Fundação para as Artes e Tecnologias Criativas do Reino Unido (FACT, em inglês), Laura Sillars, sugere uma outra abordagem, em que há uma divisão em três espectros de audiência (Sillars, 2009, p. 8). A primeira é a plateia presencial, aquela que assiste ao evento no local e na hora em que ocorre. Tradicionalmente, a primeira plateia dos Yes Men é composta por executivos, representantes governamentais e acadêmicos, e eventualmente profissionais da imprensa, que estão acostumados à dinâmica daqueles eventos, respeitam seus ritos e etiquetas, e não tem nenhum interesse em oferecer mais do que uma bovina complacência. "As pessoas que frequentam conferências corporativas são incapazes e relutantes em questionar sua própria legitimidade. De fato, estas conferências existem para maximizar e expandir redes de legitimidade", afirma Sillars (2009, p. 9). Ainda que seja parte fundamental e indispensável para a ação, esta primeira plateia não é a destinatária final dos Yes Men.

O segundo espectro de audiência é o público que consome a mídia gerada sobre a ação, após sua revelação como farsa. Um procedimento indispensável para o risoativismo dos Yes Men é publicamente revelar que a ação se tratou de um prank ${ }^{17}$, de uma impostura, e que o primeiro espectro de audiência foi enganado deliberadamente ${ }^{18}$. Mike Bonanno diz que há um ethos nos Yes Men: "nunca deixamos uma mentira sobre a mesa" (Bonanno, 2012, p. 54). Geralmente a revelação se dá através de um comunicado de imprensa, enviado tanto aos jornalistas que cobriram o evento in loco quanto aos demais canais de comunicação. Neste comunicado, além de revelar a farsa,

o grupo se justifica, dando as informações necessárias para que o público secundário se informe sobre determinado problema, denúncia ou posição pretendida pela ação. Este texto de revelação é particularmente importante, já que é a oportunidade que os Yes Men têm de veicular claramente seus interesses. Eles partem do pressuposto de que os jornalistas geralmente têm vontade de pautar assuntos relevantes, mas não conseguem fazê-lo por razões editoriais, sejam econômicas (ofensa potencial aos anunciantes, e consequente diminuição da arrecadação em publicidade) ou políticas (oposição à linha política ou aos grupos políticos vinculados à editora). Os comunicados de imprensa dos Yes Men pretendem "fazer o trabalho dos jornalistas para eles", oferecendo um texto conciso, bem humorado, com fotos e vídeos de boa qualidade, e com pesquisas em fontes confiáveis que sustentem o que está sendo 
defendido. Por isso, o trabalho de documentação e pesquisa é parte fundamental do risoativismo do grupo (Bichlbaum, 2012, p. 125). O segundo espectro de audiência tem contato, portanto, com o trabalho jornalístico feito sobre estes comunicados de imprensa emitidos pelos Yes Men. Este segundo público identifica que o primeiro espectro de audiência foi "enganado", e que agora eles estão "melhor informados" do que os espectadores presenciais. A composição desta segunda audiência reúne tanto simpatizantes quanto opositores das ações do grupo e das mensagens políticas por elas expressas, o que a caracteriza como muito mais heterogênea do que a primeira audiência. Também, por conta da mediação da imprensa, os Yes Men não têm pleno controle sobre a edição das informações que serão veiculadas, o que faz com que a comunicação com esta segunda audiência se dê de maneira indireta.

Em minha tese de doutorado me contentei apenas em distinguir estes dois espectros de audiência. Ao caracterizar o que chamava prank de simulação, propunha que havia o primeiro nível de audiência, os que estiveram presentes e foram ludibriados pela simulação, e o segundo nível, cúmplice dos risoativistas, que seria composto por aqueles que viram a ação a posteriori, através da mídia (Salvatti, 2010, p. 66). No entanto, é preciso reconhecer que a análise de Laura Sillars é mais apropriada, já que adiciona um terceiro espectro de audiência neste esquema. Enquanto a audiência de segundo nível seria aquela que consome o noticiário ou o veículo de comunicação em que repercute a revelação da impostura, e cuja composição é heterogênea, a audiência de terceiro nível é aquela que assiste aos filmes dos Yes Men, que acompanha seu site, que lê seu livro, etc. Quando esta audiência acessa o conteúdo produzido pelos Yes Men, ele já está devidamente editado pelos risoativistas (e não só pela imprensa). Ou seja, as melhores e mais espetaculares cenas já foram selecionadas, os efeitos visuais e sonoros já foram incluídos para, com auxílio da edição, maximizar o efeito cômico, a narrativa do clipping de imprensa já está trabalhada para que a argumentação do grupo seja privilegiada. Há um controle do grupo sobre forma e conteúdo, que faz com que esta terceira audiência seja praticamente unânime em seu suporte estético e político aos Yes Men. Dos três espectros, é o que tem a composição mais homogênea, já que é a que mais tende a concordar e replicar as ideias e metodologias dos risoativistas. A terceira audiência estabelece com a primeira uma relação de superioridade ainda maior do que a segunda já estabelecia: além das entidades que estão tendo suas identidades corrigidas, também são alvo do riso as reações de surpresa, confusão ou mesmo de apatia da primeira audiência. Este terceiro espectro, podemos concluir, é a audiência preferencial das ações dos Yes Men. Do mesmo modo que no espectro de alianças, a opção pelo risoativismo seria, portanto, uma tática para aumentar o volume desta terceira audiência, seduzindo representantes da segunda audiência através do humor.

O texto de Laura Sillars foi publicado em um catálogo de uma exposição feita sobre o trabalho do grupo, em 2009. Além desta exposição individual, os Yes Men

\footnotetext{
${ }^{17}$ Uma das traduções possíveis para prank é pegadinha, uma brincadeira conhecida por expor ao ridículo um determinado alvo. "Um prank é um golpe, um trote, um chiste, ainda que sua tradução se perca entre estas diferentes palavras. Se quisermos, prank pode ser algo como 'pregar uma peça', uma travessura, uma sabotagem. Pressupõe irreverência, uma certa molecagem desautorizadora". Salvatti, 2010. p. 2.

${ }^{18}$ Este procedimento é o que difere as ações dos Yes Men do Teatro Invisível de Augusto Boal. Neste último são representadas cenas que geram algum dilema político, social ou moral no espaço público e as testemunhas não tem a informação de que se trata de uma ficção, nunca se revela que se trata de uma ação teatral. Boal pretendia que, ao serem expostos a estes dilemas, as testemunhas refletissem sobre suas decisões.
} 
mostraram seus trabalhos em várias exibições de arte (dentre as quais a Bienal do Whitney, a Bienal de Veneza, a ARS Eletrônica) e receberam vários prêmios e recursos destinados a produção artística, predominantemente relacionados aos filmes que eles produzem. Ainda que reconheçam um vínculo possível entre a política e arte, curiosa e sintomaticamente, os Yes Men não reivindicam para si o status de artistas. Preferem a qualificação ativismo criativo, mas mantém com o circuito da arte contemporânea uma relação quase que utilitária. Esta distância do projeto artístico parece denotar uma certa desconfiança dos Yes Men em relação a uma função social ou política da arte, ou ao menos em relação à institucionalização da arte contemporânea. Ainda assim, é inegável que suas práticas adotam transversalmente conceitos estéticos presentes na história e teoria da arte.

Nosso trabalho é ativismo criativo, mas isso depende apenas de quem o observa. Tanto faz o modo como as pessoas enxergam nosso trabalho. [...] Não nos importamos muito com isso [com a arte], apesar de ser uma chance de contarmos a nossa história de uma outra maneira. Com frequência, financiamos o nosso trabalho por meio da arte. Temos conseguido algum dinheiro através desse canal. ${ }^{19}$

O crítico de arte John Byrne, no entanto, reconhece que o trabalho do grupo atende aos dois principais critérios que ele identifica como indispensáveis para que uma obra de arte contemporânea seja bem sucedida. Primeiro, são radicais tecnicamente, e, segundo, a intenção crítica de suas ações (revelar e perturbar o fluxo do capitalismo corporativo) os afilia com as práticas engajadas das vanguardas artísticas:

É precisamente neste ponto, entre a dominação da arte como mercadoria espetacular e a dissolução da arte per se, que encontramos o trabalho dos Yes Men. Eles são capazes de usar e manipular a mídia para seus objetivos, assim como uma agência de publicidade de alto padrão. Que eles sejam capazes de fazer isso a preço de banana, usando técnicas de guerrilha e explorando redes de distribuição virais, evidencia sua habilidade de clonar o mecanismo de desinformação corporativa que buscam criticar. (Byrne, 2009, p. 21)

Esta legitimação tanto pela crítica de arte quanto pela pesquisa acadêmica nos conduzem a por em questão o potencial subversivo dos Yes Men. É certo que eles conquistaram, ao longo de sua trajetória, reconhecimento por seu humor ácido e sarcástico, e um exemplo disso é que a renomada jornalista anti-globalização Naomi Klein os chamou de "os Jonathan Swift da geração Jackass". No entanto, pesa sobre eles, assim como sobre boa parte dos ativistas que adotam o riso ou elementos festivos e carnavalescos em suas manifestações, diversas críticas sobre a efetividade de suas táticas.

Uma primeira categoria de crítica, mais geral, é uma desconfiança da competência da comédia em ser utilizada como instrumento político. Stephen Halliwell é incisivo: "A comédia é, por sua própria natureza, politicamente impotente já que é aparentemente permissiva, uma forma de alívio temporário que reforça a ordem social existente e não faz nada, no fim das contas, para mudá-la" (Byrne apud Stott, 2014, p. 154). Para esta opinião, haveria uma espécie de impotência ontológica da comédia frente à política. Independentemente dos inúmeros exemplos da articulação

\footnotetext{
${ }^{19}$ Mike Bonanno em entrevista para André Mesquita em 09 de fevereiro de 2006. Mesquita, 2008, p. 325.
} 
entre humor e política na história das ideias, Georges Minois tem opinião ainda mais negativa:

O recurso sistemático à derrisão não tem os efeitos que poderiam ser esperados. A zombaria política generalizada, longe de desembocar na subversão, acaba contribuindo para banalizar as práticas que denuncia. Os meios políticos conseguem exterminar o cômico, tornando-se eles próprios cômicos. [...] Um poder que não aceita zombaria é um poder ameaçado, desprezado, votado a desaparecer. As democracias modernas aceitam o contrapoder do riso porque avaliaram sua utilidade. [...] O caricaturista, o intelectual zombador, o comediante parodístico apenas retomam o papel do bufão do rei. Ora, o bobo do rei nunca pôs em risco a monarquia, ao contrário. $\mathrm{O}$ humorista político contemporâneo não ameaça os políticos do momento, e estes evitam puni-lo. (Minois, 2003, p. 596-597)

Ou seja, pior do que a impotência política que Halliwell atribui ao humor, Minois identifica um papel negativo do humor nas estruturas políticas, já que ele poderia ser recuperado pelo poder como instrumento conservador em vez de subversivo.

Uma segunda categoria de crítica questiona a utilização da resistência política no campo simbólico frente à dominação do capital neoliberal. Mesmo Geert Lovink, formulador do conceito de mídia tática, reconhece seu limite:

Grupos de mídia tática não podem e não devem ser instrumentalizados e colocados em evidência como grandes exemplos. Isso apenas nos levará à decepção e ao afastamento. Certos trabalhos podem inspirar e se propagar como memes. Mas eles não são capazes de igualar-se aos grandes problemas do mundo. [...] O que está em jogo aqui é a capacidade das ações. Quantos memes podemos mudar? Como podemos olhar para a mudança da relação entre a nova mídia e os canais oficiais de transmissão? E quais são as consequências da mídia tática? Desculpe, mas o midiativismo simplesmente não cumpre essa tarefa. Da mesma maneira, também não acredito que a "questão da mídia" esteja no centro do problema, ou ela mesma seja a causa do problema (quanto mais a solução). ${ }^{20}$

O que Lovink aponta, a incapacidade de igualar os memes aos problemas do mundo, talvez seja uma observação até mais relevante hoje do que há dez anos, quando concedeu esta entrevista ${ }^{21}$. Operar no campo simbólico não pode substituiruma resistência material, concreta, que envolva pessoas reais e alvos também reais. De fato, mesmo os Yes Men reconhecem as limitações de suas táticas, assumindo que elas não seriam úteis sem uma forma tradicional de resistência. "A organização real é a única forma útil de ativismo. Há uma série de atividades que são mais importantes do que aquilo que fazemos: processos, agitação, organização, passeatas, etc."22

Por fim, uma terceira categoria de crítica é aquela que articula as duas primeiras, a limitação da comédia frente a política e a limitação do ativismo simbólico frente as demandas concretas da resistência. Seria, portanto, uma crítica específica ao uso do humor para propósitos ativistas, ou seja, uma crítica do risoativismo. Os franceses Laurent Jeanneau e Sébastien Lernould apresentam elementos desta crítica. Primeiro, contrapondo a noção de espetáculo ético de Ducombe, fazem uma crítica direta aos Yes Men, por vilipendiar as engrenagens da globalização neoliberal, mas ainda

\footnotetext{
${ }^{20}$ Geert Lovink em entrevista para André Mesquita em 07 de março de 2006. Mesquita, 2008, p. 308.

${ }^{21}$ Suponho que Lovink não esteja denotando o uso comum do termo meme nos dias de hoje, ou seja, uma imagem ou som com uma mensagem jocosa que pretende uma viralização em redes sociais. Em vez disso, imagino que Lovink esteja pensando na formulação original do termo, pelo biólogo Richard Dawkins, que considerava o meme um equivalente cultural do gene, ou seja, uma unidade mínima de cultura capaz de se auto-replicar através da imitação.
} 
assim extrair lucro na venda de seus livros e DVDs. “Denunciar o espetáculo das aberrações capitalistas é um mercado lucrativo, com uma forte demanda" (Jeanneau e Lernould, 2008, p. 64). Em seguida, ao comparar os militantes da geração francesa de 1968 com o que chamam de "novos militantes", os militantes contemporâneos, ecoam a base da primeira categoria de crítica descrita acima, ou seja, que a comédia pode ser muito ineficiente como tática política:

Os novos militantes evoluem no sistema, na realidade em si. [...] Não se opõem aos modos de ação política clássicos, mas os complementam. Deste ponto de vista, o riso pode ser um vetor de mobilização. Ele não trata de negar a seriedade dos processos políticos de fundo, mas de apenas dar cor a um militantismo monótono e grisalho. Colar nele uma etiqueta cool sem ter a arrogância de querer mudar a face do mundo. Modesto, se comparado ao projeto político situacionista. (Jeanneau e Lernould, 2008, p. 65)

Se, por um lado, é razoavelmente simples avaliar eficiência e eficácia no plano do ativismo político, considerando quais foram os objetivos traçados pela estratégia e verificando se foram ou não atingidos (exemplo: se o objetivo for interromper uma votação na Câmara dos Deputados em determinada data, a eficácia da estratégia selecionada só pode ser confirmada ou negada), por outro, a verificação de cumprimento de objetivos no plano simbólico é menos simples. A correção de identidade quer ser um golpe no capital simbólico acumulado por determinada entidade. Como aferir se este capital sofreu um impacto pela ação ou não? Como avaliar se o bobo da corte pôs em risco a monarquia ou não? Bichlbaum diz que a medida não pode ser se determinado problema foi resolvido, mas se uma nova luz, uma nova atitude foi praticada sobre o problema. Deste modo, mesmo se determinada ação ou o conjunto de trabalho de determinado grupo não for considerado eficaz, a aferição real só pode se dar na avaliação do movimento de ativistas no qual aquela ação ou grupo se insere.

Como Edward Snowden, nós queremos jogar pelas regras da democracia, o que para nós significa construir pressão pública para expor informação crítica. E esta informação deve ser a informação real. Nós contamos com a comédia e com a mordacidade de nossas ações para ganhar atenção pública, mas quando mentimos para a imprensa é por um curto período, a serviço da comédia, e a mentira é logo revelada: o conteúdo da "revelação" deve ser totalmente verdadeiro. [...] As revelações de Snowden trouxerem à luz muito do que estava escondido; nós, em contraste, só trazemos um pouco mais de claridade e visibilidade pública coisas que estavam meio obscuras. [...] Esse é o jeito que as ações midiagênicas podem se encaixar no quadro de ações efetivas. ${ }^{23}$

Parcialmente motivados por estas dúvidas, desejosos de estabelecer com suas práticas uma relação também pedagógica, em 2010 os Yes Men seguiram a trajetória do Otpor! e propuseram também o projeto de um centro de treinamento para ativistas. Trata-se do Yes Lab ${ }^{24}$, um laboratório sem fins lucrativos para oferecer workshops e sessões de brainstorming destinados a multiplicar a experiência em risoativismo adquirida. A urgência dos Yes Men de contribuir com a formação de novos ativistas é equivalente à necessidade que eles têm de se divertirem com suas ações. O Yes Lab é um modo de convidar novos participantes para se divertirem juntos. 
O funcionamento do Yes Lab se dá da seguinte forma: organizações ativistas procuram o laboratório com um determinado alvo e objetivo. Os Yes Men trabalham com estas organizações remota ou presencialmente para criar as ações, escolher as táticas mais apropriadas, conduzir workshops e treinamentos que forem necessários e acompanhar o desenvolvimento do projeto até sua execução e finalização. Os conteúdos dos workshops geralmente incluem 1) apresentação sobre o risoativismo e sobre o ativismo direcionado a captar a atenção da mídia; 2) processos e práticas de brainstorming de projetos; 3) planejamento do projeto, com cronogramas, deadlines, cadeia de responsabilidades e checklists; 4) treinamento em relação à imprensa, improvisação, escrita, filmagem, webdesign e edição de vídeo; 5) mapeamento das habilidades e das necessidades materiais para execução do projeto.

No outono de 2011, o Yes Lab estabeleceu uma parceria com o Instituto Hemisférico de Performance e Política, vinculado à New York University e com uma longa história de vínculo com grupos artistas e ativistas. O Yes Lab passou a ter um escritório dentro do Hemi, além de suporte institucional e infraestrutural. Em contrapartida, os workshops do laboratório passaram a ser oferecidos também para os alunos da universidade. Além disso, Andy Bichlbaum passou a ser professor visitante do Departamento de Estudos da Performance da NYU no semestre seguinte.

A parceria entre Yes Lab e Hemi coincidiu com a eclosão, a partir de setembro, do movimento Occupy Wall Street, no qual ativistas de vários lugares dos Estados Unidos e de fora do país ocuparam a praça Zuccotti, próxima à emblemática rua em que está localizada a bolsa de Nova York e que é o símbolo máximo do capital financeiro. Sob o lema de "nós somos os 99\%", uma referência à porcentagem da população mundial excluída dos lucros obtidos pelo cassino global dos mercados financeiros, os ativistas reunidos pelo Occupy Wall Street conseguiram chamar a atenção para a desigualdade econômica predominante no capitalismo atual.

A participação do Yes Lab no OWS foi bastante significativa. Em uma das ações orquestradas pelo laboratório, dois palhaços invadiram na área cercada ao redor do Touro de Wall Street, escultura de bronze de 3,4 metros de altura que simboliza a agressividade do Distrito Financeiro. A escultura havia sido cercada para impedir que os ativistas a depredassem. Por isso, um destacamento policial fora encarregado para garantir a segurança do touro. Tão logo os dois palhaços invadiram a área cercada, os policiais se encarregaram de algemá-los. Enquanto estavam ocupados com isso, os policiais não perceberam a aproximação de um toureiro vestido a caráter, que subiu com seu manto vermelho no alto da viatura e fez o célebre gestual chamando o touro para um duelo. A imagem que registrou a ação se tornou um dos emblemas do movimento. ${ }^{25}$

\footnotetext{
${ }^{23}$ Entrevista a Victor Peterson. In: Martin, 2015, p. 197.

${ }^{24}$ yeslab.org
} 


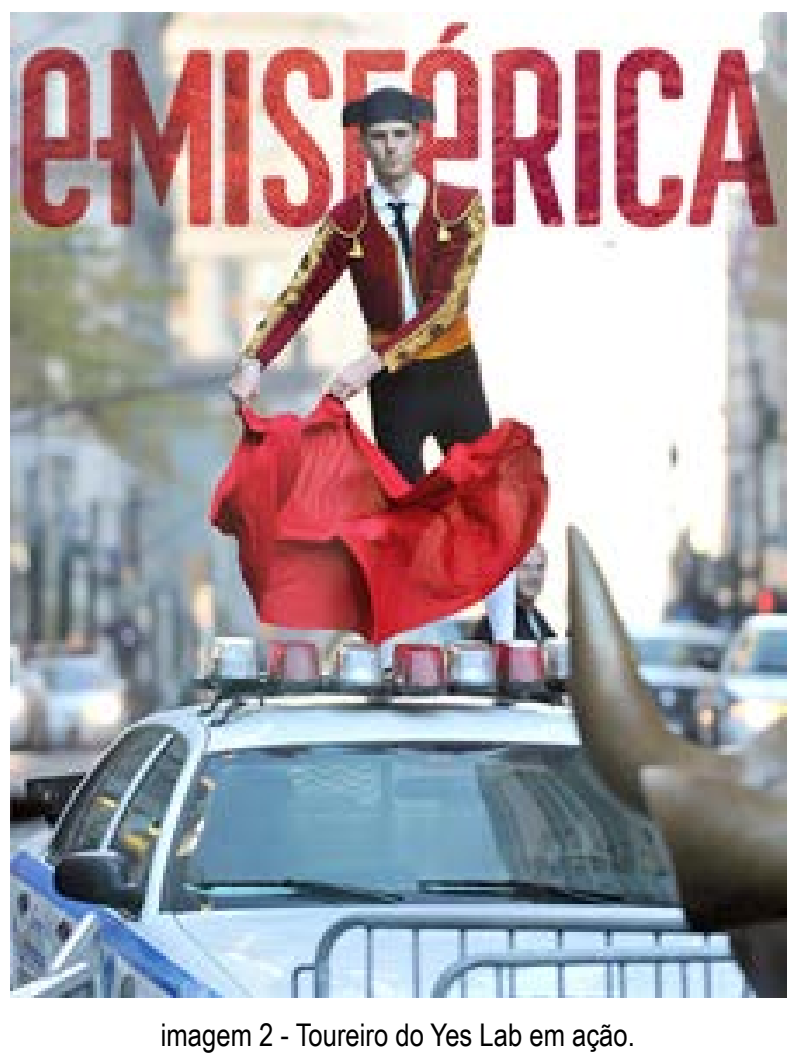

Imagem selecionada para a capa da $10^{\circ}$ edição da e-misférica, revista do Instituto Hemisférico de Performance e Política / NYU

Há uma demonstração nesta iniciativa, a meu ver, de uma ampliação de foco do Yes Lab. Ainda que as ações realizadas especificamente pelos Yes Men se mantenham risoativistas, me parece que a valorização pedagógica do laboratório quer contemplar um espectro mais amplo de possibilidades de táticas reunidas sobre o adjetivo criativo. Ainda que o humor se mantenha como qualidade importante, não se mantém como objetivo exclusivo a ser perseguido pelo Yes Lab. Antes da criação do laboratório, os Yes Men já tinham uma orientação pedagógica em seu risoativismo (já que suas ações sempre buscaram, de algum modo, informar e educar, através da mídia, as audiências secundárias e terciárias a respeito de temas que os ativistas consideram relevantes). Também os Yes Men frequentemente realizaram palestras a respeito de sua trajetória, quando convidados por universidades, por instituições culturais e por organizações ativistas. Ainda, Andy e Mike, quando não estão personificando portavozes corporativos, disfarçam-se de professores: ambos tem carreiras acadêmicas e lecionam em diferentes universidades nos Estados Unidos. No entanto, mesmo considerando esta experiência prévia, é possível afirmar que é com o Yes Lab que a perspectiva pedagógica de formação de um ativista criativo toma espaço e corpo como eixo importante de trabalho dos Yes Men. Mesmo com as críticas, aqui já apresentadas, ao ativismo realizado no campo simbólico de modo geral e ao risoativismo de modo particular é importante perceber que o laboratório desenvolvido pelo grupo é uma instância de formação política do não-ativista e de formação técnico-política do artista-ativista (ou artivista).

${ }^{25} \mathrm{Um}$ excelente vídeo da ação está disponivel em https://www.youtube.com/watch?v=pfrf71ALsEs 


\section{Referências}

BICHLBAUM, Andy. Identity Correction. In: BOYD, Andrew (Org.). Beautiful trou ble: a toolbox for revolution. Nova York: OR Books, 2012.

BONANNO, Mike. Dow Chemical apologizes for Bhopal. In: BOYD, Andrew (Org.). Beautiful trouble: a toolbox for revolution. Nova York: OR Books, 2012.

BOYD, Andrew (Org.). Beautiful trouble: a toolbox for revolution. Nova York: OR Books, 2012.

BYRNE, John. The Yes Men: art and the culture of corporate capital. In: SUPARAK, Astria (org.). Keep it slick - infiltrating capitalism with the Yes Men. Catálogo para exposição homônima na Miller Gallery na Carnegie Mellon University, Pittsburg, 2009.

DUCOMBE, Stephen. Ethical Spectacle. In: BOYD, Andrew (Org.). Beautiful trou ble: a toolbox for revolution. Nova York: OR Books, 2012.

JEANNEAU, Laurent e LERNOULD, Sébastien. Les Nouveaux Militants. Paris: Lespetits matins, 2008.

MARTIN, Randy (org.). The Routledge Companion to art and politics. Nova York: Routledge, 2015.

MESQUITA, André. Insurgências Poéticas - arte ativista e ação coletiva (19902000). Dissertação de mestrado apresentada ao Programa de Pós-Graduação em História da FFLCH - USP. São Paulo, 2008.

MINOIS, Georges. História do riso e do escárnio. São Paulo: Unesp, 2003.

POPOVIC, Srdja e ALVAREZ, Marcella. Laughtervism. Strike Magazine, 07 de mar ço de 2014. Disponível em http://strikemag.org/laughtervism/

POPOVIC, Srdja e MILLER, Matthew. Blueprint for revolution: how to use rice pudding, lego men and other nonviolent techniques to galvanize communities, overthrow dictators, or simply change the world. Nova York: Penguin, 2015.

SALVATTI, Fabio. O prank como opção performativa para a rede de ativismo político contemporâneo. Tese de doutorado apresentada ao Programa de Pós-Gra duação em Artes Cênicas da ECA-USP. São Paulo, 2010.

SILLARS, Laura. Yes Men fans of the world, unite! Or how to deal with anti-social situations and indiffe rent communities. In: Astria (org.). Keep it slick - infiltrating capitalism with the Yes Men. Catálogo para a exposição homônima na Miller Gallery na Carnegie Mellon University, Pittsburg, 2009. 
STOTT, Andrew. Comedy. Nova York: Routledge, 2014.

SUPARAK, Astria (org.). Keep it slick - infiltrating capitalism with the Yes Men. Catálogo para exposição homônima na Miller Gallery na Carnegie Mellon Uni versity, Pittsburg, 2009.

VALE, V. Entrevista com Mike Bonanno. Pranks \#2 San Francisco: RE/Search Pu blications, 2006, p. 32-43.

VANDERBILT, Tom. On the Yes Men. Artforum Magazine, fevereiro de 2005. Dis ponivel em https://artforum.com/inprint/issue $=2005028$ id $=8261$

THE YES MEN. The Yes Men: the true story of the end of the world trade organi zation. Nova York: The Disinformation Company, 2004.

THE YES MEN, Yes Lab Cookbook Archive, arquivos de trabalho não publicados recebidos por e-mail em 10 fev. 2015.

Filmes:

BICHLBAUM, Andy e BONANNO, Mike. The Yes Men fix the world. 2009.

BICHLBAUM, Andy, BONANNO, Mike, NIX, Laura. The Yes Men are revolting. 2014.

OLLMAN, Dan; PRICE, Sarah e SMITH, Chris. The Yes Men, 2003.

Sites:

nytimes-se.com

yeslab.org

yesmen.org

Recebido em: 01/05/2016

Aprovado em: 02/07/2016 